\title{
Opinion Leaders and Lead Users in Marketing and Management Accounting and Impact on Small Business Performance
}

\author{
Katharina Simbeck \\ Entrepreneurship and Innovation Management, Technical University, Berlin, Germany \\ Email: ksimbeck@campus.tu-berlin.de
}

Received November 10, 2012; revised November 16, 2012; accepted January 8, 2013

\begin{abstract}
This paper empirically investigates into the business performance benefit that lead users or opinion leaders among small business owners draw from their higher involvement in management accounting or marketing topics. This work also contributes to a better identification of network members' roles solely through their ties between each other. Indeed, lead users and opinion leaders can be differentiated by a higher degree centrality in comparison to their peers. However, being an opinion leader or a lead user does not yield a measurable business benefit to the small businesses studied in this sample.
\end{abstract}

Keywords: Social Network Analysis; Opinion Leaders; Lead Users; Small Businesses; Network Centrality

\section{Introduction}

The concept of opinion leadership was introduced by the sociologists Lazarsfeld et al. [1] for a sub-group of individuals who have the power to shape a group's perceptions. The concept of "lead users" was developed by von Hippel $[2,3]$ to characterize a sub-set of product users that are ahead to their peers in terms of developing new product needs. Von Hippel [2] argues that those lead users can be closely integrated into new product development. The concept of opinion leaders was subsequently taken up also by researchers in marketing, aiming to understand how opinion leaders can be used to speed up new product diffusion. Companies turn to lead users to co-innovate relevant new products which have the potential of bigger commercial success [4]. Identifying lead users and opinion leaders may significantly improve marketing efficiency by targeting the right customers at the right point in time of product life cycle at optimized cost. Hence research in marketing has a track record of identifying opinion leaders and lead users and their characteristics (see for example Darden [5]).

The concept of opinion leadership and lead user property are widely used in social network analysis as they emerge in the interaction between subjects and can thus be considered as truely "social" properties of subjects. So far, opinion leaders and lead users are being identified using standard questionnaires or observed behavior (e.g. purchase of product at early stage of product lifecycle).
With the increasing diffusion of electronic networks, waste amounts of data on network position become available. It is therefore of interest to identify lead users and opinion leaders solely based on network data as it is potentially cheaper and faster in comparison to using questionnaires or observing behavior.

Belz and Baumbach [6] have shown that using internet ethnography methods ("netnography"), namely the analysis of posts in internet forums, classifies almost half of internet users correctly as lead users/non-lead users. Bilgram et al. [7] have also studied internet communities and identified several factors for the identification of lead users, such as "being ahead of market trend, high expected benefits" or user expertise. Even though Belz and Baumbach [6] and Bilgram et al. [7] refer to data available electronically on the internet, their approaches still require comprehensive analysis of opinions expressed in online communities. Hill et al. [8] successfully identified potential customers to be targeted through marketing by using real telecommunications data on people connected to adopters of the product.

In contrast Kratzer [9] have found out that lead users and opinion leaders among school children with regards to toys can be distinguished by specific ego-network properties, specifically betweenness for lead users and degree centrality for opinion leaders.

In a given network structure, ego has a given set of ego-network properties, e.g. a given centrality or betweenness. However with regards to opinion leadership 
or lead user role ego can have different different interests for different subjects. The groups of opinion leaders and lead users tend to overlap [10]. That overlap was theoretically confirmed by Bilgram et al. [7]. Spann [11] argue that opinion leadership is a characteristic of the lead user variable and therefore use an opinion leader questionnaire as one of three criteria in identifying lead users. The object of this research is to study the ego-network properties and lead user/opinion leader roles for two management subjects, namely marketing and management accounting.

Thus this research aims to contribute to a better understanding of network members solely through their ties between each other. Based on the empirical data used for this research lead users and opinion leaders cannot be really differentiated based on ego network properties. However, the tendency that lead users have a higher number of contacts especially on a national as opposed to local level, i.e. degree centrality and opinion leaders are located on more paths between others (i.e. higher betweenness centrality) can be confirmed. Furthermore we find that lead users or opinion leaders do not benefit from their higher involvement in management accounting or marketing topics through better business performance.

\section{Theory}

\subsection{Network Position and Network Role}

Two distinctive network roles will be discussed: lead users and opinion leaders. Lead users apply innovations faster in comparison to peers. Opinion leaders communicate more than others on specific topics.

\subsection{Network Position}

Social network analysis has defined various concepts to describe the position of an actor in a network. Centrality is one of the concepts most frequently used. There are several definitions for the centrality of an actor. It can be defined among others based on the number of direct contacts (degree centrality) or based on the paths between other actors that go through the actor (betweenness centrality) $[12,13]$.

Degree centrality can be interpreted as a measure of potential communication activity whereas betweenness is interpreted as the opportunity to control communication [13]. Betweenness centrality measures on how many paths between other actors an actor lies and such potentially controls their communication $[11,12]$. The property of the ego-network can further by characterized by closeness centrality: This measure measures centrality in terms of distance or closeness relative to the other actors in the network [12].

\subsection{Opinion Leaders}

The concept of opinion leadership was described in soci- ology first by Lazarsfeld et al. in his classical study on opinion formation during presidential election campaign in 1944 in Erie Countie [1]. Unexpectedly for the authors, the study revealed, that mass media do not impact the opinion of people directly but through opinion leaders [1]. The concept of opinion leadership was developed in the framework of political convictions, but later applied vastly to consumer behavior from a marketing perspective [14]. The opinion leadership attribute is linked to a certain subject or area of interest, such as a product category. Different persons can be opinion leaders for different matters. In fact, King and Summers [15] found that less than one third of almost 1000 respondents could not be considered as opinion leader in one of 6 types of product. However, opinion leaders for one product category are likely to be opinion leaders for other, especially adjacent categories, as well [15].

Feder and Savastano [16] have studied the role of opinion leaders in the diffusion of innovations on the example of pest control tools used by Indonesian farmers. They conclude that opinion leaders facilitate the diffusion of knowledge when they are only moderately more successful (measured as socio-economic distance) than followers.

\subsection{Lead Users}

A further classical study reveals the concept of lead users: von Hippel [2] names such the group of product users, who require certain features earlier than the mass market and take advantage of innovations in this direction strongly. Von Hippel [2] proposes to use lead users and their specific requirements for market research purposes. Today some companies establish relationships with lead users to create product innovations [17].

Companies attempt to to use lead users to create and identify relevant innovation [3]. Ideas generated by lead users tend to be more commercially relevant, strategic and innovative [4]. Lead users can be identified by using a questionnaire; by screening customer databases or by contacting product users and asking for referrals to other users other needs [17]. Lead users tend to be more experienced and possess a higher level of knowledge in a certain domain [18]. Schreier [18] propose to use knowledge and experience in combination with the individual properties internal locus of control and innovativeness to identify lead users. Spann [11] show how virtual stock markets can be used to identify lead users for consumer products.

Jeppesen and Laursen [19] find that lead users in an online community do not only acquire new knowledge outside the community but also import it into the community, this indicates that lead users might be especially valuable acquaintances for other veterinarians. 


\subsection{Association between the Network Roles and Ego-Network Position}

Without using the later developed concepts of lead users or opinion leaders, Coleman [20] discuss the impact of social ties to peers on innovation diffusion, namely the adoption of a new drug among physicians in a city. They find that those physicians that are friends with many others, adopt the innovative drug earlier [20]. Kratzer and Lettl [9] have shown, that lead users can be distinguished by high betweenness centrality whereas opinion leaders by high degree centrality. The link between opinion leadership and network centrality is also confirmed by Merwe [21]. Iyengar et al. [22] however find that opinion leadership and central network position correlate but do not completely overlap. They find that central network position is actually a better measure of influencing leadership as opinion leadership identified through sociometric questionnaires [22]. Cho et al. [23] model the impact of network position on innovation diffusion using various centrality concepts; however they implicitly assume that lead users are always opinion leaders for the innovation. In this specific application of the research question two different sets of lead users and opinion leaders are analyzed: those for marketing and those for management accounting questions. One agent with a given network position can or cannot be a lead user/opinion leader in both fields.

Often, a strong relationship between domain specific opinion leadership (i.e. in a certain field) and general opinion leadership is found: opinion leaders in one field tend to consider themselves as opinion leaders in other fields [18]. This leads to the first hypotheses.

H1 Network position is associated with opinion leader role.

H1a The higher the degree centrality of a business owner, the more likely the business owner can be identified as an opinion leader.

$\mathrm{H} 2$ Network position is associated with lead user role.

H2a The higher the betweenness centrality of a business owner, the more likely the business owner can be identified as a lead user.

\subsection{Network Role and Performance}

Interestingly spread of innovation is often considered a similar process to learning. Literature describes both opinion leaders and lead users as interested and knowledgeable in their respective specialties. According to von Hippel [2] lead users have a higher perceived need for innovations which results in a higher perceived benefit from adapting innovations. However, being a lead user can also yield other benefits, such as peer recognition [19]. Usually lead users and opinion leaders are assessed by researchers with regards to their "usefulness" [17,23,
24,31]: How can they help to promote a product or a healthcare treatment? What is the best approach to reach lead users fast to establish a user base for an innovative product? To our knowledge the outcome of opinion leadership or lead user property on the subject is not studies so far. The concept and definition of lead users integrates that the first adopters of an innovation are those that benefit most from it economically.

Opinion leaders are not only expected to share their knowledge [25]. This could lead to the conclusion, that opinion leaders and lead users are better in marketing or management accounting activities than their colleagues and consequently perform better with their businesses. This leads to hypothesis H3:

H3: Opinion leadership and lead user property are positively related with performance.

On the other hand, lead users are expected to try out a greater variety of activities.

\section{Description of Sample and Measures}

A survey based empirical analysis of veterinarians in Berlin is used to understand to what extend the hypotheses are correct or need to be rejected. The survey was sent out to all veterinarians practicing in Berlin from the complete list of the Veterinary Chamber's website, downloaded in July 2010. The focus was on small animal practices.

After removing veterinarians who do not practice anymore or are specialized on horses or pathology and consolidating those veterinarians practicing in a joint practice/partnership, a base sample size of 324 practices remains. The base universe consists of 283 single practices and 41 partnerships. In single practices, 138 veterinarians are male and 145 female. In the base universe 8 partnerships are male only, 17 female and 16 of mixed gender (see Table 1).

Out of 121 valid answers received, 20 were from partnerships whereas 101 were single practices. The average age of respondents was 50 years (approximated as 2010 year of birth). Practices were established on average since 15 years (approximated as 2010 - year of establishment), 32 practices are young practices $(<8$ years of establishment). Practices had on average 2.2 veterinary assistants (including trainees) and employed 2.0 veterinarians including owner(s). Not all questionnaires were returned $100 \%$ filled. Those with missing answers were excluded pair wise for analysis.

There might be a non-response bias in the data from practices with lower turnover because those practices might be less interested in management questions. Table 2 shows the distribution of turnover in the sample and in the base universe. There is no data available on turnover for veterinary practices for Berlin. The sample data can be compared to the German average turnover of small 
Table 1. Distribution in sample and base universe.

\begin{tabular}{|c|c|c|c|c|c|c|c|}
\hline & male & $\%$ & female & $\%$ & mixed & $\%$ & Total \\
\hline \multicolumn{8}{|c|}{ Base Universe } \\
\hline Total & 146 & $45.10 \%$ & 162 & $50.0 \%$ & 16 & $4.9 \%$ & 324 \\
\hline Single practice & 138 & $48.80 \%$ & 145 & $51.2 \%$ & & & 283 \\
\hline Partnership & 8 & $19.50 \%$ & 17 & $41.5 \%$ & 16 & $39.0 \%$ & 41 \\
\hline \multicolumn{8}{|c|}{ Sample } \\
\hline Total & 56 & $46.30 \%$ & 58 & $47.9 \%$ & 7 & $5.8 \%$ & 121 \\
\hline Single practice & 50 & $49.50 \%$ & 51 & $50.5 \%$ & & & 101 \\
\hline Partnership & 6 & $30.00 \%$ & 7 & $35.0 \%$ & 7 & $35.0 \%$ & 20 \\
\hline \multicolumn{8}{|c|}{ Response Rate } \\
\hline Total & $38 \%$ & & $36 \%$ & & $44 \%$ & & $37 \%$ \\
\hline Single practice & $36 \%$ & & $35 \%$ & & & & $36 \%$ \\
\hline Partnership & $75 \%$ & & $41 \%$ & & $44 \%$ & & $49 \%$ \\
\hline
\end{tabular}

Table 2. Turnover distribution in sample and base universe.

\begin{tabular}{|c|c|c|c|c|c|c|c|}
\hline \multicolumn{4}{|c|}{ Sample (Berlin only) } & \multicolumn{4}{|c|}{ Small Animal Practices, GermanyDESTATIS (2009, p. 117) } \\
\hline Turnover in 1000 Eur & Cases & Grouped & $\%$ & Turnover in 1000 Eur & Cases & Grouped & $\%$ \\
\hline$<40$ & 11 & & & & & & \\
\hline $40-80$ & 22 & & & & & & \\
\hline $80-125$ & 24 & 57 & $53.3 \%$ & $<125$ & 1567 & 1567 & $53.0 \%$ \\
\hline $125-250$ & 31 & 31 & $29.0 \%$ & $125-250$ & 909 & 909 & $30.8 \%$ \\
\hline \multirow[t]{2}{*}{$>250$} & 19 & 19 & $17.8 \%$ & $250-500$ & 398 & 479 & $16.2 \%$ \\
\hline & & & & $>500$ & 81 & & \\
\hline Total cases & 107 & 107 & & & 2955 & 2955 & \\
\hline
\end{tabular}

animal veterinary practices as collected by the German Federal Statistical Office [26]. The distribution of the turnover is surprisingly close to the distribution of turnover within veterinarians in Germany overall. This indicates a good representation of practices in the sample. On the other hand it needs to be expected that the turnover in Berlin is comparably low [27]. 14 respondents did not answer the question concerning their sales. The difficult financial situation of veterinarians is comparable to the one of other freelance professions: In his detailed study of freelance engineering offices, Hommerich [28] finds that about two thirds of the engineers had an annual profit of less than 25,000 Eur, the average turnover per person employed including owner was 62,000 Eur [28].

The average response rate was $37 \%$, which is a very satisfying response rate for this kind of survey.

\subsection{Performance Measurement}

In this study turnover will be used for measuring performance. Turnover is used for three reasons: first, it is easy to survey in the questionnaire. Second turnover is less subject to tax optimizing efforts. Third it is assumed that veterinary practices in Berlin have a similar cost structure. Furthermore, veterinarians are expected to share turnover more willingly with researcher than profit figures. The turnover of small animal veterinarians consists of several main components: on the one hand turnover from both curative and preventive veterinary services, on the other hand turnover from the sale of products (drugs, pet food, dietary supplements). The sale of products as opposed to services is linked to an own set of managerial questions such as capital lockup in inventory, optimization of order quantity, losses because of aging.

\subsection{Measuring Network Position}

In order to assess the network positions of the small businesses, every respondent was provided a list of all veterinarians practicing in Berlin. Respondents were asked to tick those of their peers, with whom they are acquainted. The data was coded using 3-digit numbers. Further, small 
business owners were asked how many peers they are acquainted with on a nationwide and potentially international level, which can also be interpreted as a degree centrality measure.

For every small business owner the properties of the ego-network were calculated using UCInet [29] and entered into the dataset for further statistical analysis, namely degree centrality, in-degree centrality, out-degree centrality, and betweenness. The complete network is shown in Figure 1.

\subsection{Measures for Opinion Leader and Lead User Quality}

Opinion leaders can be identified using the sociometric approach (typical question: "To whom do you refer to obtain information about..."), the key informant method (by asking knowledgeable individuals) or through selfdesignation (using a questionnaire) [30]. The sociometric and the self-designation approaches are both widely used. Interventions with the aim of improving medical practice usually through opinion leaders usually use the sociometric approach [31]. Researchers aiming to use opinion leaders to improve understanding of marketing processes often turn to the King-Summers questionnaire [15,32].

According to Lazarsfeld et al. [1] opinion leaders will answer the the following two questions positively:

- Have you lately consulted somebody in matters of ...?

- Has somebody asked you for advice lately in matters of ...?

Fenton [33] have developed a questionnaire consisting of six questions for opinion leadership that that is the base for most questionnaires used today. Furthermore Schenk [14] cites expertise and personal involvement as further pre-requisites for opinion leadership. This is operationalized in the questionnaire through the question "I am earlier informed on new developments than others."

The lead user concept was developed by von Hippel [2] to describe those users of new products that have specific needs earlier than typical users of the product category.

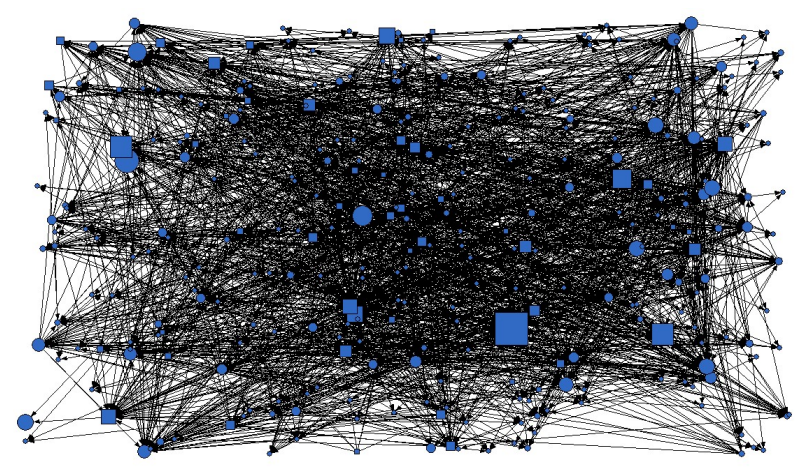

Figure 1. Complete Network: node size represents betweenness; box shape represents high lead user score.
In this research however the focus is on new developments in management, namely marketing and management accounting. Small business owners with a nonmanagement background face the challenge to compete not only using their specialist knowledge, but also management processes, i.e. to gain new customers or to take wise investment decisions. Within the set of businesses competing in a certain market, some will be very advanced with regards to marketing and management accounting processes while others will not care. By identifying lead users of innovative management accounting and marketing processes we will be able to test whether those have specific network properties and whether their innovative approach contributes to their business performance.

Separate scales are built for the roles in marketing and in management accounting: a person with a deep interest in marketing might not have the same interest for management accounting. The opinion leader scale for this study is built using the items "I recently consulted somebody", "Others ask my advice", and "I am earlier aware than others about new developments". The lead user scale uses the items "I am usually one of the first to try out", "I have done specific trainings", "I like talking about ...", and "I continuously read and learn about..."

Both scales were tested for scale reliability with excellent results: Cronbach's Alpha was $>0.8$ for both opinion leader and lead user scales for both fields of interest marketing and management accounting. In comparison to other studies, opinion leadership and lead userness correlate relatively strong in this dataset: $r=0.732$ for marketing and $r=0.810$ for management accounting. The correlation between network role for marketing and management accounting respectively is also high: $\mathrm{r}=$ 0.660 for opinion leader attribute and $r=0.707$ for lead user attribute. This indicates a very high overlap of lead users and opinion leaders for marketing and management accounting.

\subsection{Control Variables}

The average performance indicators are significantly higher for male veterinarians. Consequently, gender of the practice owner is used as a control variable. It takes a certain time until a practice has found a sufficient number of clients and after a certain number of years of practice, the curve of customer base growth and management learning flattens. The variable "years of establishment" was approximated as the research year (2010) minus the year of founding. The Variable "years of establishment" is transformed into a dichotomous variable "young practice" which was set if the age of the practice is $<8$ years and which is used as a control variable.

The concept of market orientation was described and operationalized by Jaworski [35]; Kohli and Jaworski [36] 
and Narver and Slater [37] in the beginning of the 1990s. The model brought forward by Kohli and Jaworski [36] (abbreviated MARKOR) focuses on the elements of the marketing process (intelligence generation, intelligence dissemination and responsiveness. The authors predict a strong link to company performance [35]. This has been confirmed in many studies [34]. Therefore market orienttations shall be used as a control variable for the test of the relationship between opinion leadership/lead userness and performance.

The original scale to measure market orientation contained 32 items and was proposed by them in 1993 [35]: 10 items to analyze marketing intelligence generation, 8 items for market intelligence dissemination, and 14 with regards to the responsiveness ( 7 for response design and 7 for response implementation) [35]. While the questionnaire was shortened for the scope of this research, the categories remained: marketing intelligence generation is represented by marketing research (data collection), dissemination is represented by marketing research (data analysis), response design is represented by marketing strategy and response implementation is represented by marketing strategy implementation. The scale was tested successfully for reliability (Cronbach's alpha 0.706).

\section{Results}

In line with prior studies $[6,10]$, we find a relatively high overlap between lead users and opinion leaders. This agrees also with prior findings that lead users are not only combining new insights from the outside with existing knowledge to create innovation but are also located at the center of information sharing within their community [19].

For correlation and regression analysis joint practices and practices specializing in surgery, odontology or ophthalmology are excluded as they rely on recommendations from other veterinarians. Correlation analysis (Table 3) shows, that both lead userness and opinion leadership for marketing correlate significantly with in-degree centrality. This is in line with the expectation from hypothesis H1a that opinion leadership is linked to central network position. Business owners that are well informed about developments in management accounting and marketing and like to share that knowledge tend to be known by numerous peers. On the other hand, there is no significant correlation for out-degree centrality. Outdegree centrality measures how many peers a business owner cites as contacts where as in-degree centrality refers to the number of times somebody gets cited.

Citing many others as contacts is not linked to opinion leadership nor to lead userness. The number of veterinary contacts in Germany can be interpreted as a further degree centrality measure looking at a national level, while the other network figures measure the veterinary network in the city of Berlin only. The number of veterinary contacts in Germany is as expected also significantly and

Table 3. Correlation between network position and network role.

\begin{tabular}{|c|c|c|c|c|c|c|c|c|c|c|c|c|c|c|c|c|}
\hline & & $\mathrm{N}$ & 1 & 2 & 3 & 4 & 5 & 6 & 7 & 8 & 9 & 10 & 11 & 12 & 13 & 14 \\
\hline 1 & Age & 90 & 1 & & & & & & & & & & & & & \\
\hline 2 & Gender & 99 & $0.302^{* *}$ & 1 & & & & & & & & & & & & \\
\hline 3 & $\begin{array}{c}\text { Young Company } \\
(<8 \text { years })\end{array}$ & 99 & $-0.620^{* *}$ & $-0.407^{* *}$ & 1 & & & & & & & & & & & \\
\hline 4 & Market Orientation & 83 & 0.005 & $0.297^{* *}$ & -0.098 & 1 & & & & & & & & & & \\
\hline 5 & Degree Centrality & 99 & 0.107 & -0.139 & -0.197 & 0.127 & 1 & & & & & & & & & \\
\hline 6 & $\begin{array}{c}\text { Betweenness } \\
\text { Centrality }\end{array}$ & 99 & 0.192 & 0.021 & -0.174 & 0.201 & $0.482^{* *}$ & 1 & & & & & & & & \\
\hline 7 & $\begin{array}{c}\text { \# of peer contacts } \\
\text { in Germany }\end{array}$ & 88 & 0.119 & -0.023 & -0.140 & 0.165 & $0.479^{* *}$ & $0.330^{* *}$ & 1 & & & & & & & \\
\hline 8 & Turnover & 86 & -0.142 & $0.415^{* *}$ & -0.140 & $0.456^{* *}$ & 0.151 & $0.256^{*}$ & -0.019 & 1 & & & & & & \\
\hline 9 & $\begin{array}{l}\text { Opinion Leader } \\
\text { Marketing }\end{array}$ & 95 & 0.055 & $0.278^{* *}$ & -0.166 & $0.406^{* *}$ & 0.114 & $0.290^{* *}$ & $0.343^{* *}$ & $0.308^{* *}$ & 1 & & & & & \\
\hline 10 & $\begin{array}{l}\text { Lead User } \\
\text { Marketing }\end{array}$ & 92 & -0.038 & $0.214^{*}$ & -0.060 & $0.574^{* *}$ & 0.166 & $0.367^{* *}$ & 0.215 & $0.385^{* *}$ & $0.656^{* *}$ & 1 & & & & \\
\hline 11 & $\begin{array}{l}\text { Opinion Leader } \\
\text { Controlling }\end{array}$ & 95 & 0.037 & $0.304^{* *}$ & -0.198 & $0.306^{* *}$ & 0.024 & 0.094 & $0.315^{* *}$ & $0.280 * *$ & $0.594^{* *}$ & $0.533^{* *}$ & 1 & & & \\
\hline 12 & $\begin{array}{l}\text { Lead User } \\
\text { Controlling }\end{array}$ & 95 & 0.084 & 0.194 & -0.156 & $0.550^{* *}$ & 0.060 & 0.116 & $0.266^{*}$ & $0.293^{* *}$ & $0.522^{* *}$ & $0.674^{* *}$ & $0.757^{* *}$ & 1 & & \\
\hline 13 & $\begin{array}{l}\text { In Degree } \\
\text { Centrality }\end{array}$ & 99 & 0.156 & 0.120 & -0.083 & 0.135 & $0.481^{* *}$ & $0.543^{* *}$ & $0.417^{* *}$ & $0.313^{* *}$ & $0.254^{*}$ & $0.251^{*}$ & 0.124 & 0.115 & 1 & \\
\hline 14 & $\begin{array}{c}\text { Out Degree } \\
\text { Centrality }\end{array}$ & 99 & 0.113 & -0.144 & $-0.224^{*}$ & 0.167 & $0.744^{* *}$ & $0.654^{* *}$ & $0.348^{* *}$ & 0.152 & 0.120 & 0.198 & 0.047 & 0.061 & 0.185 & 1 \\
\hline
\end{tabular}

${ }^{*} \mathrm{p}<0.05 ;{ }^{* *} \mathrm{p}<0.01 ;{ }^{* * *} \mathrm{p}<0.001 ;$ two-tailed. 
positively correlated with opinion leader role. Thus H1a can be confirmed based on correlation analysis.

The results for lead userness are less clear. The correlation between lead userness and betweeness correlates positively and significantly for marketing, but not so for management accounting. The assumption from hypothesis H2a that lead users in management processes are located between sub-groups in the peer network and thus act as linking elements cannot be fully confirmed at this stage.

A hierarchical linear regression analysis on standardized independent variables is performed to validate those findings. The significance levels of all regression coefficients are determined using bootstrapping.

In a first step linear regression with opinion leader quality being the dependent variable is calculated for control variables (see Table 4). The regression based on age and gender explains only $4.9 \% / 6.6 \%$ of variance in opinion leader quality for marketing/management accounting respectively. Introducing the ego network variables of degree centrality, betweenness and number of veterinary contacts in Germany increases the explained variance to $20.6 \% / 16.3 \%$ for marketing/management accounting respectively. The results are less clear then the ones by Kratzer and Lettl [9] who can explain about $40 \%$ of the variance. Still, the regression co-efficients for number of veterinary contacts in Germany which is also a measure of degree centrality are significantly positive in both models. As a conclusion $\mathrm{H} 1$ and $\mathrm{H} 1 \mathrm{a}$ is confirmed. However there are indications that the number of local contacts to peers has a negative effect. Interestingly, opinion leaders can be identified in this dataset not so much by the number of peers they know locally but more so by the number of peers they know on a nationwide level.

A similar hierarchical linear regression analysis is performed to research the relationship between network

Table 4. Regression analysis opinion leader role.

\begin{tabular}{|c|c|c|c|c|}
\hline \multicolumn{3}{|c|}{ Marketing } & \multicolumn{2}{|c|}{ Management Accounting } \\
\hline \multicolumn{5}{|c|}{ 1. Regression with control variables } \\
\hline Age of Owner & 0.030 & -0.046 & -0.019 & -0.045 \\
\hline Gender & $0.260^{*}$ & $0.235^{*}$ & $0.304^{*}$ & $0.296^{*}$ \\
\hline corr. $\mathrm{R}^{2}$ & 0.049 & & 0.066 & \\
\hline Sig. & 0.053 & & 0.027 & \\
\hline \multicolumn{5}{|c|}{ 2. Regression with network variables } \\
\hline \# of peer cont & cts within city & $-0.235^{*}$ & \multicolumn{2}{|c|}{-0.164} \\
\hline Betw & nness & $0.298^{* *}$ & \multicolumn{2}{|c|}{0.029} \\
\hline \# of peer cont & ts in Germany & $0.388^{*}$ & \multicolumn{2}{|c|}{$0.404 *$} \\
\hline cor & $\mathrm{R}^{2}$ & 0.206 & \multicolumn{2}{|c|}{0.163} \\
\hline & & 0.001 & \multicolumn{2}{|c|}{0.003} \\
\hline
\end{tabular}

${ }^{*} \mathrm{p}<0.05 ;{ }^{* *} \mathrm{p}<0.01 ;{ }^{* * *} \mathrm{p}<0.001 ;$ two-tailed. position and lead user quality. Again, regression is calculated for control variables first (see Table 5). The regression based on age and gender explains only $3.5 \% / 1.4 \%$ of variance in lead user quality for marketing/management accounting respectively. Introducing the ego network variables of degree centrality, betweenness centrality and number of veterinary contacts in Germany increases the explained variance to $19.9 \% / 8.0 \%$ for marketing/management accounting respectively.

In comparison to the opinion leader regression model the effect of betweenness is stronger and for marketing opinion leadership also significant. The importance of betweenness centrality and thus hypotheses $\mathrm{H} 2 \mathrm{a}$ for lead userness can only partially be confirmed through linear regression (only for the model on opinion leadership for marketing, not for management accounting). Hypothesis $\mathrm{H} 2$ can be confirmed as the explained variance increases significantly in both models. Figures 2 and $\mathbf{3}$ represent the ego networks of 2 selected nodes with high/low lead user scores.

In order to test hypothesis H3 correlation analysis is performed between the performance measure turnover and opinion leader/lead user factors. It turns out that both opinion leadership and lead userness correlate significantly with performance. On the other hand the correlations for the control variables, namely market orientation was strong as well. Consequently two-step hierarchical regression analysis (Table 6) is applied in order to model the effects of opinion leadership and lead userness on top to the control variables. It becomes apparent that contrary to the hypothesis neither opinion leadership nor lead userness contributes to explaining performance. The positive correlation between performance and opinion leadership/lead userness is fully moderated by market orientation.

Thus, neither lead users nor opinion leaders can translate their assumed knowledge advantage into busines

Table 5. Regression analysis lead user role.

\begin{tabular}{ccccc}
\hline & Marketing & \multicolumn{3}{c}{ Management Accounting } \\
\hline & 1. Regression with control variables \\
Age of Owner & -0.085 & -0.188 & 0.064 & 0.033 \\
Gender & $0.258^{*}$ & $0.223^{*}$ & 0.168 & 0.164 \\
corr. R & 0.035 & & 0.014 & \\
Sig. & 0.096 & 0.212 & \\
& 2. Regression with network variables
\end{tabular}

$\begin{array}{ccc}\text { \# of peer contacts within city } & -0.142 & -0.110 \\ \text { Betweenness } & 0.435^{* *} & 0.037 \\ \text { \# of peer contacts in Germany } & 0.195 & 0.347 \\ \text { corr. } \mathrm{R}^{2} & 0.199 & 0.080 \\ \text { Sig. } & 0.001 & 0.046 \\ { }^{*} \mathrm{p}<0.05 ;{ }^{* *} \mathrm{p}<0.01 ;{ }^{* * *} \mathrm{p}<0.001 ; \text { two-tailed. } & \end{array}$




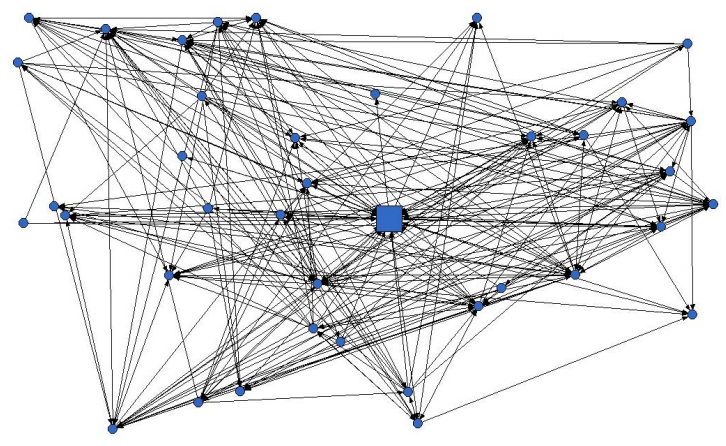

Figure 2. Ego network of node 115 (high opinion leader/lead user score).

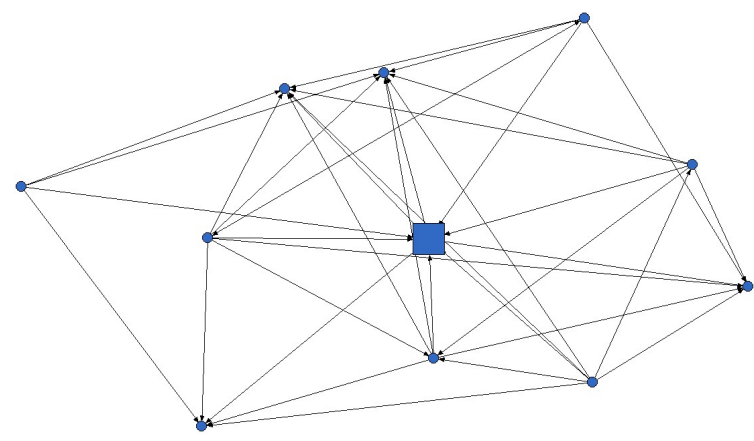

Figure 3. Ego network of node 285 (low opinion leader/lead user score).

Table 6. Regression Analysis Performance.

\begin{tabular}{ccc}
\hline & \multicolumn{2}{c}{ Turnover } \\
\hline 1. Regression with control variables \\
Age of Owner & $-0.205^{*}$ & $-0.192^{*}$ \\
Gender & $0.337^{* *}$ & $0.319^{* *}$ \\
Market Orientation & $0.361^{* * *}$ & $0.378^{* *}$ \\
corr. $\mathrm{R}^{2}$ & 0.307 & \\
Sig. & 0.000 & \\
2. Regression with network variables \\
Opinion Leader Marketing & -0.041 \\
Lead User Marketing & 0.212 \\
Opinion Leader Controlling & 0.198 \\
Lead User Controlling & -0.310 \\
corr. R ${ }^{2}$ & 0.303 \\
Sig. & 0.000 \\
\hline
\end{tabular}

performance, however they have a higher probability of being market oriented which itself relates to successful performance. The concept of lead userness implies that innovations are adapted earlier because of their needs. It must be concluded that lead users adapt innovations earliers not only for business reasons but also to meet other needs, such as peer recognition or the joy of trying out something new (see also [19]). Opinion leaders are keen on sharing knowledge, which might not even benefit themselves in terms of business performance.

\section{Discussion and Conclusion}

The objective of this research was twofold: on the one hand we wanted to reconfirm the approach to identify lead users and opinion leaders based on ego network properties proposed by Kratzer and Lettl [9]. In order to do so we replicated their experiment in a different location with a different test group. We identified lead users and opinion leaders in marketing and management accounting among Berlin based veterinarians using a questionnaire. We also studied the network properties of the veterinarians by asking them to which other veterinarians they are acquainted.

The second objective of this research was to study the link between opinion leadership and performance and between lead user property and performance. We tested whether the lead users and opinion leaders identified in marketing and management accounting did perform better in business. The results of this study show that this is not the case. The higher involvement in marketing and management accounting does not yield a measurable business benefit to the small businesses studied in this sample.

\subsection{Implications for Theory}

This research contributes to social network analysis, lead user/opinion leadership research and entrepreneurship research. With regards to social network analysis we confirm that degree centrality can be used to identify opinion leaders and potentially also lead users. Further we find a difference between local and national networks. Being acquainted with more distant peers increases the likelihood of being an opinion leader. Further we contribute to a better understanding of both antecedents (network position) and consequences (business performance) of lead user and opinion leader properties. Central network position, i.e. being acquainted with peers is an antecedent of opinion leadership. Being acquainted with peers outside the local market and network seems to be especially important. In contrast to the hypothesis, neither opinion leadership nor lead user attribute in management accounting or marketing are associated with better business performance. In this respect this reseach also adds to the complex field of success factor research in entrepreneurship: a higher interest in management topics does not seem to pay out for entrepreneurs.

\subsection{Implications for Practice}

From a network analysis point of view, we can confirm that ego-network structure, especially degree centrality 
can help to identify high-involvement persons with a higher probability of being lead users or opinion leaders and thus improve targeting of marketing measures. Marketeers that are trying to identify lead users and opinion leaders based on network data should also consider the difference between local acquaintances and more distant acquaintances. According to the findings in this paper, network members which are not only well connected on a local level but also on a wider, say nationwide level, are more likely to be opinion leaders or lead users. Since opinion leaders or lead users in marketing and management accounting do not show superior business performance, scholars and consultants in management should refrain from over-estimating the impact of their science. Practioneers should focus on improving market orientation much more then marketing or management accounting skills.

\subsection{Limitations and Directions}

The explained variances in the models are relatively small. With regards to the identification of opinion leaders and lead users future research should try to find further criteria which can be used to improve identifycation of lead users or opinion leaders besides ego- network data.

This could be information that is available in electronic social networks such as hobbies or preferences or information available in different databases such as turnover with older product versions. Further, the data does not differentiate well between lead users and opinion leaders, which might be due to the fact that we have not used product innovations but management processes as subject.

With regards to the impact of lead user property and opinion leadership in management on performance it needs to be acknowledged that this may depend on size, industry or complexity of the business. Also, innovative new ventures might well benefit from technology lead users in their management team while other service businesses might benefit from opinion leaders in the specific service field in their sales team. The role of lead users and opinion leaders for business performance thus deserves further studies.

\section{REFERENCES}

[1] P. P. F. Lazarsfeld, B. Berelson and H. Gaudet, "Wahlen und Wähler," Luchterhand, Neuwied, 1969.

[2] E. von Hippel, "The Sources of Innovation (The Executive Bookshelf from the Sloan Management Review)," Oxford University Press, Oxford, 1988.

[3] E. von Hippel, "Lead Users: A source of Novel Product Concepts," Management Science, Vol. 32, No. 7, 1986. pp. 791-805. doi: 10.1287/mnsc.32.7.791
[4] I. Eisenberg, "Lead-User Research for Breakthrough Innovation," Research Technology Management, Vol. 54, No. 1, 2011. pp. 50-58.

[5] W. R. Darden and F. D. Reynolds, "Predicting opinion leadership for men's apparel fashions," Journal of Market Research, Vol. 9, No. 3, 1972, pp. 324-328. doi: $10.2307 / 3149547$

[6] F. M. Belz and W. Baumbach, "Netnography as a Method of Lead User Identification," Creativity and Innovation Management, Vol. 19, No. 3, 2010, pp. 304-313. doi:10.1111/j.1467-8691.2010.00571.x

[7] V. Bilgram, A. Brem, K.-I. Voigt, "User-Centric Innovations in New Product Development-Systematic Identification of Lead Users Harnessing Interactive and Collaborative Online-Tools," International Journal of Innovation Management, Vol. 12, No. 3, 2008, pp. 419-458. doi:10.1142/S1363919608002096

[8] S. Hill, F. Provost and C. Vollinsky, "Network-Based Marketing: Identifying Likely Adopters via Consumer Networks," Statistical Science, Vol. 21, No. 2, 2006, pp. 256-276. doi:10.1214/088342306000000222

[9] J. Kratzer and C. Lettl, "Distinctive Roles of Lead Users and Opinion Leaders in the Social Networks of Schoolchildren," Journal of Consumer Research, Vol. 36, No. 4, 2009, pp. 646-659. doi:10.1086/599324

[10] P. D. Morrison, J. H. Roberts and D. F. Midgley, "Opinion Leadership Amongst Leading Edge Users," Australasian Marketing Journal, Vol. 8, No. 1, 2000, pp. 5-14. doi:10.1016/S1441-3582(00)70181-9

[11] M. Spann, H. Ernst, B. Skiera and J. H. Soll, "Identification of Lead Users for Consumer Products via Virtual Stock Markets," Journal of Product Innovation Management, Vol. 26, No. 3, 2009, pp. 322-335. doi:10.1111/j.1540-5885.2009.00661.x

[12] S. Wasserman and K. Faust, "Social Network Analysis: Methods and Applications (Structural Analysis in the Social Sciences)," 1st Edition, Cambridge University Press, Cambridge, 1994. doi:10.1017/CBO9780511815478

[13] L. C. Freeman, "Centrality in Social Networks Conceptual Clarification," Social Networks, Vol. 1, No. 3, 1978. pp. 215-239. doi:10.1016/0378-8733(78)90021-7

[14] M. Schenk, "Finanz-Meinungsführer," Spiegel Verlag, 2005.

[15] C. King and J. Summers, "Overlap of Opinion Leadership Across Consumer Product Categories," Journal of Marketing Research, Vol. 7, No. 1, 1970, pp. 43-50. doi: $10.2307 / 3149505$

[16] G. Feder and S. Savastano, "The Role of Opinion Leaders in the Diffusion of New Knowledge: The Case of Integrated Pest Management," Policy Research Working Paper Series, The World Bank, No. 3916, 2006.

[17] C. Luthje and C. Herstatt, "The Lead User Method: An Outline of Empirical Findings and Issues for Future Research," R\&D Management, Vol. 34, No. 5, 2004, pp. 553-568.doi:10.1111/j.1467-9310.2004.00362.x

[18] M. Schreier and R. Pruegl, "Extending Lead-User Theory: Antecedents and Consequences of Consumers' Lead Userness," The Journal of Product Innovation Manage- 
ment, Vol. 25, No. 4, 2008, pp. 331-346. doi:10.1111/j.1540-5885.2008.00305.x

[19] L. B. Jeppesen and K. Laursen, "The Role of Lead Users in Knowledge Sharing," Research Policy, Vol. 38, No. 10, 2009, pp. 1582-1589. doi:10.1016/j.respol.2009.09.002

[20] J. Coleman, E. Katz and H. Menzel, "The Diffusion of an Innovation among Physicians," Sociometry, Vol. 20, No. 4, 1957, pp. 253-270. doi:10.2307/2785979

[21] R. Merwe and G. V. Van Der Heerden, "Finding and Utilizing Opinion Leaders: Social Networks and the Power of Relationships," South African Journal of Business Management, Vol. 40, No. 3, 2009, pp. 65-77.

[22] R. Iyengar, C. van den Bulte, J. Eichert, B. West and T. W. Valente, "How Social Networks and Opinion Leaders Affect the Adoption of New Products," GfK Marketing Intelligence Review, Vol. 3, No. 1, 2011. pp. 16-26.

[23] Y. Cho, J. Hwang and D. Lee, "Identification of Effective Opinion Leaders in the Diffusion of Technological Innovation: A Social Network Approach," Technological Forecasting and Social Change, Vol. 79, No. 1, 2012. pp. 97-106. doi:10.1016/j.techfore.2011.06.003

[24] R. A. Coulter, L. F. Feick and L. L. Price, "Changing Faces: Cosmetics Opinion Leadership among Women in the New Hungary," European Journal of Marketing, Vol. 36, No. 11-12, 2002, pp. 1287-1308. doi:10.1108/03090560210445182

[25] W. Hoyer and J. Jacoby, "What if Opinion Leaders Didn't know more? A question of Nomological Validity," Advances in Consumer Research, Vol. 8, 1955, pp. 299-303.

[26] DESTATIS, Kostenstruktur bei Arzt- und Zahnarztpraxen, Praxen von psychologischen Psychotherapeuten Sowie Tierarztpraxen, Fachserie 2. Statistisches Bundesamt. 2009.

[27] S. Bundesamt, "Einkommensteuer: Statistik 2004," Deutsches Tierärzteblatt, Vol. 8, 2009, pp. 1036-1037.

[28] V. C. Hommerich, "Controlling Ist Zwingend Geboten," Deutsches IngenieurBlatt, No. 6, 2007, pp. 42-45.
[29] S. P. P. Borgatti, L. Everett and C. Freeman, "UCINET 6 for Windows: Software for Social Network Analysis," 2002.

[30] R. E. Goldsmith and R. Desborde, "A Validity Study of a Measure of Opinion Leadershipp," Journal of Business Research, Vol. 22, No. 1, 1991. pp. 11-19. doi:10.1016/0148-2963(91)90010-U

[31] G. Flodgren, E. Parmelli, G. Doumit, M. Gattellari, M. A. O'Brian, J. Grimshaw and M. Eccles, "Local Opinion Leaders: Effects on Professional Practice and Health Care Outcomes (Review)," The Cochrane Library, Vol. 8, 2011.

[32] L. R. Flynn, R. E. Goldsmith and J. K. Eastman, "The King and Summers Opinion Leadership Scale: Revision and Refinement," Journal of Business Research, Vol. 31, No. 1, 1994, pp. 55-64. doi:10.1016/0148-2963(94)90046-9

[33] J. S. Fenton and T. R. Leggett, "A New Way to Find Opinion Leaders," Journal of Advertising Research, Vol. 11, No. 2, 1971, pp. 21-26.

[34] C. Rodriguez Cano, F. A. Carillat and F. Jaramillo, "A Meta-Analysis of the Relationship between Market Orientation and Business Performance: Evidence from Five Continents," International Journal of Research in Marketing, Vol. 21, No. 2, 2004, pp. 179-200. doi:10.1016/j.ijresmar.2003.07.001

[35] B. J. Jaworski and A. K. Kohli, "Market Orientation: Antecedents and Consequence," Journal of Marketing, Vol. 57, No. 3, 1993, p. 53. doi:10.2307/1251854

[36] A. K. Kohli and B. J. Jaworski, "Market Orientation: The Construct, Research Propositions, and Managerial Implications," Journal of Marketing, Vol. 54, No. 2, 1990, pp. 1-18. doi:10.2307/1251866

[37] J. C. Narver and S. F. Slater, "The Effect of a Market Orientation on Business Profitability," Journal of Marketing, Vol. 54, No. 4, 1990, pp. 20-35. doi: $10.2307 / 1251757$ 